\title{
From pathogenesis to treatment, a systemic review of cardiac lipoma
}

\author{
Shenglei Shu ${ }^{1,2}$, Jing Wang ${ }^{1,2}$ and Chuangsheng Zheng ${ }^{1,2^{*}}$ (D)
}

\begin{abstract}
Cardiac lipoma is an uncommon primary cardiac tumor. With the advancement of diagnostic methods and treatment techniques, more cases of cardiac lipomas have been reported and suggest that the entity previously widely thought to display classic features may also show atypical findings. A systemic review of the rare cardiac tumor was done by searching the literature of cardiac lipoma. We endeavor to summarize the clinical features of the rare disease from pathogenesis to treatment. Literature of cardiac lipoma was retrospectively searched through PubMed and 255 cases of cardiac lipoma were included into this analysis. Cardiac lipomas can occur anywhere within the heart, $53.1 \%$ were located within the cardiac chambers, $32.5 \%$ in the pericardium, $10,7 \%$ within the myocardium and $3.7 \%$ involved multiple structures. More than half of the reported cardiac lipomas (66\%) may be clinically symptomatic, presenting with symptoms ranging from chest discomfort to syncope depending on their size and location as well as extent of myocardial involvement. Noninvasive cardiac imaging has replaced the role of autopsy and cardiothoracic surgery in detection and diagnosis of cardiac lipomas. Most symptomatic patients (83.7\%) were treated by resection of cardiac lipomas and $68.3 \%$ of asymptomatic patients also underwentprophylactic resection. Overgrowth and myocardial infiltration of lipomas may result in unsuccessful resection. Recurrence of cardiac lipomas was rare but reported in a few cases. The early detection and accurate diagnosis of cardiac lipoma is of great significance in clinical management, to avoid an unfavourable outcome due to overgrowth.
\end{abstract}

Keywords: Cardiac lipoma, Noninvasive diagnosis, Clinical management, Systemic review

\section{Background}

Realdo Columbus was credited with the first report of a cardiac tumor in 1559. However, it was not until 1856 that the first cardiac lipoma was reported by Albers. The benign mass is composed of mature adipose tissue and may occur in any site where fat tissue is present. Occurrence of true lipoma within heart and pericardium is rare [1]. By the end of second decade of the twenty-first century, no more than 400 cases of cardiac lipomas had been reported. It's generally considered that most cardiac lipomas are silent, and symptomatic lipomas can be

\footnotetext{
* Correspondence: hqzcsxh@sina.com

'Department of Radiology, Union Hospital, Tongji Medical College,

Huazhong University of Science and Techonolgy, No.1277 Jiefang Avenue, Wuhan 430022, Hubei Province, China

${ }^{2}$ Hubei Province Key Laboratory of Molecular Imaging, Wuhan, China
}

treated by radical resection $[2,3]$. With the advancement of diagnostic tools and treatment techniques, the detection and diagnosis of cardiac lipoma has gained substantial progress and more cases with atypical manifestation of cardiac lipomas have been reported [3, 4]. The aim of this article is to systematically review and analyze the existing knowledge on cardiac lipoma, as well as providing a more comprehensive profile of the rare disease.

\section{Pathogenesis}

Lipomas are soft masses of fat tissue which are often encapsulated by a thin layer of fibrous tissue. Though most cardiac lipomas are composed of mature white adipose tissue, cardiac lipomas composed of fetal brown fat have also been reported in several cases [5-7]. The 
etiology of the mesenchymal tumor remains unknown. Genetic variation mostly involving the HMGA2 gene is commonly seen in extracardiac lipomas [8]. However, such cytogenetic mutation is uncommon in cardiac lipomas [9]. Multiple cardiac lipomas have been reported in several patients with tuberous sclerosis [10], but their relation is yet to be established.

The natural pathogenetic process of cardiac lipoma is not yet completely understood. On the one hand, they may be symptomatically silent for a prolonged period and even undergo necrobiotic changes [9], whereas in other instances, lipomas may grow to be very large in size with or without infiltration of the myocardium $[3,11,12]$. Pericardial lipomas may even result in myocardium resorption with cavitation and communication with cardiac chambers, thus forming a pseudoaneurysmal appearance [13-16]. In addition, solitary lipomas involving multiple cardiac cavities across the myocardium have been reported [17-19]. If they do not originate from multiple foci, it suggests that the benign mass has great capacity of infiltrative growth. The infiltrative growth pattern has been postulated as the result of gradual invagination of the firm lipomas into the pliable cavity wall within the process of repetitive systolic contraction [20]. No evidence is available that cardiac lipomas may undergo malignant transformation, but mature lipomas and well-differentiated liposarcomas may coexist within one heart [21].

\section{Epidemiology}

True lipomas with fibrous encapsulation occurring in heart and pericardium are very rare. The reported incidence of primary heart tumors in the autopsy series is between $0.2-0.4 \%[22,23]$, of which cardiac lipomas account for $8.4 \%$ [10]. As these figures include both highly encapsulated lipomas and lipomatous hypertrophy of interatrial septum, the exact incidence of cardiac lipoma may be overestimated. As for lipomas composed of fetal brown adipose tissue, the so called hibernoma, these are extremely rare in the heart and only few cases have been reported [5-7]. By searching PubMed, we found that more than 300 cases of true cardiac lipomas have been reported. Two hundred fifty-five cases of cardiac lipoma with available details were included and reviewed.

Among the included cases, no difference in the distribution of cardiac lipoma between genders (126 female, 120 male, in 9 cases gender is not available) was shown. Cardiac lipomas may occur at any age of life from the fetal period to the elderly in their 80s [24, 25]. Most cardiac lipomas occur in the $40-70$ age group $(153 / 255$, $60.0 \%$, Fig. 1). Among the included reports, 242 patients $(242 / 255,94.9 \%)$ had single cardiac lipoma, 13 patients (13/255, 5.1\%) had multiple (2 or more) cardiac lipomas. Of note, 5 encapsulated cardiac masses in 4 patients were composed of brown adipose tissue, thus constituting a diagnosis of cardiac hibernoma.

\section{Characteristics}

The different sites of origin of lipomas within the heart have not been described in detail. The commonly described locations of origin are: $25 \%$ from the subpericardium, $25 \%$ from the myocardium and 50\% from the subendocardium $[2,26,27]$. As the mechanism of cardiac lipoma formation is not yet fully understood, the

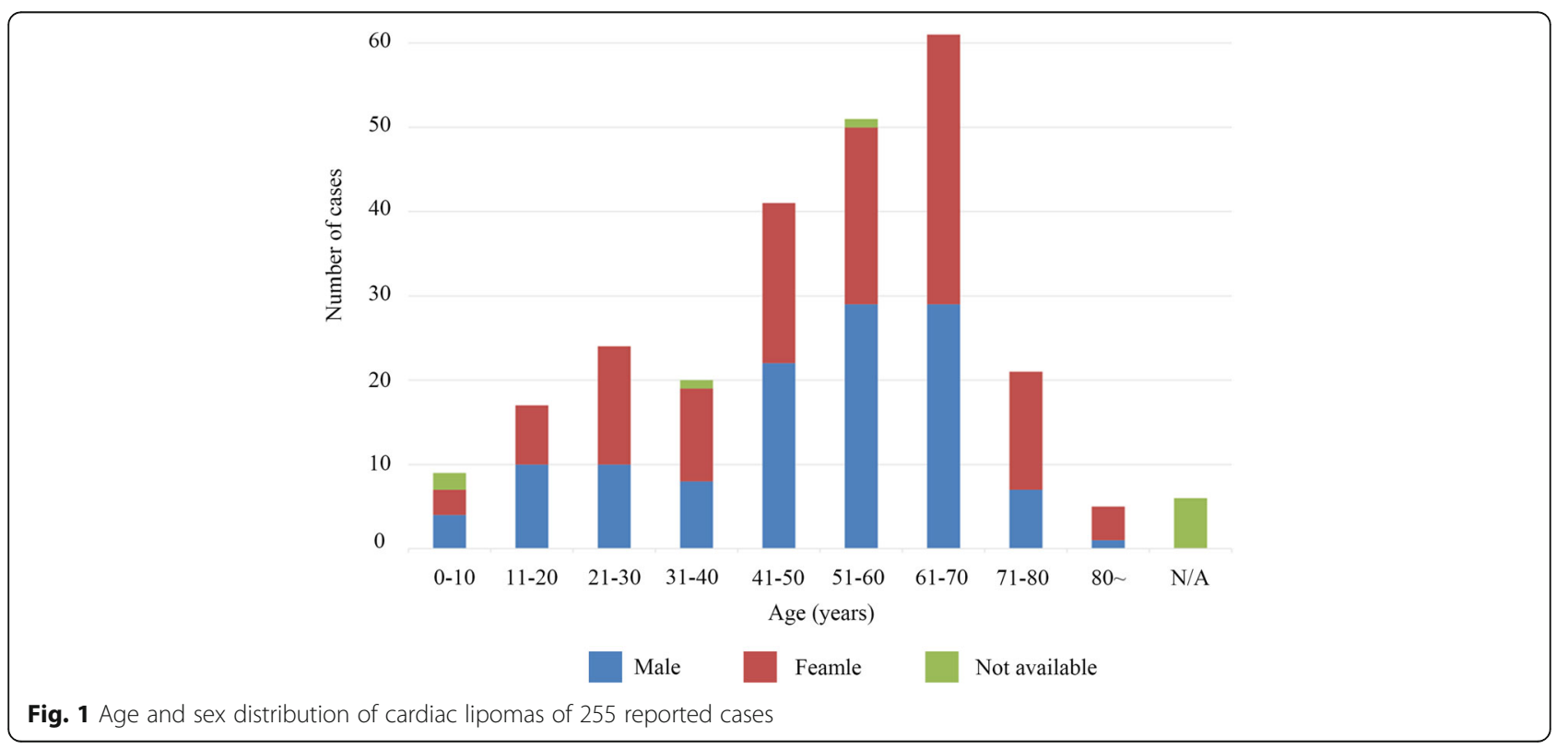


origin of cardiac lipoma is determined by the location and attachment.

By reviewing the location of cardiac lipomas in the included reports, there were more than 271 cardiac lipomas in 255 patients. 144 (144/271, 53.1\%) lipomas were located within the cardiac chambers, of which 61 $(61 / 144,42.4 \%)$ were in the right atrium, $48(48 / 144$, $33.3 \%)$ in the left ventricle, $19(19 / 144,13.2 \%)$ in the right ventricle, and $4(4 / 144,2.8 \%)$ in the left atrium (Fig. 2). In particular, 12 (12/144, 8.3\%) originated from cardiac valvular leaflets. $88(88 / 271,32.5 \%)$ lipomas were found in the pericardium. $29(29 / 271,10.7 \%)$ lipomas were located within the myocardium of ventricular or atrial wall. Although lipomatous hyperplasia is commonly seen in the atrial septum, most intramyocardial lipomas occurred within the left ventricular wall (11 in interventricular septum, 8 within free wall of left ventricle). The other 9 (9/271, 3.3\%) lipomas involved multiple chambers. One special lipoma $(1 / 271,0.4 \%)$ was found as an embolus occluding the left coronary ostium in autopsy of a patient with sudden death [28]. Their distribution within the heart suggests that around 48.7\% lipomas arise from the subendomyocardium (132/ 271), 32.5\% (88/271) from subpericardium, 10.7\% (29/ 271) from myocardium and $4.4 \%$ (12/271) from cardiac valvular leaflets. However, this may be an inaccurate analysis, as myocardial infiltration of intracardiac or intrapericardial masses may falsely suggest that the lipoma arise from the myocardium. Furthermore, the original site of a solitary lipoma involving multiple cavities across the myocardium cannot be easily determined. With more cases to be reported, the distribution of cardiac lipomas may be more accurately described in the future.

\section{Clinical presentation}

It is generally assumed that most cardiac lipomas are silent and only a small proportion of this entity may show clinical symptoms depending on their location and size [3]. However, among the included cases, only in 97 patients $(97 / 255,38.0 \%)$ were cardiac lipomas found incidentally without related symptoms. Among them, 76 cases of lipomas were detected on routine check-up or examination for other purposes (76/255, 29.8\%), 15 cases of lipomas were detected on autopsy in patients who died from other causes $(15 / 255,5.9 \%)$, and the remaining 6 patients' lipomas were discovered incidentally during surgery for other purposes $(6 / 255,2.4 \%)$. Symptoms related to cardiac lipoma were presented in 147 patients $(147 / 255,57.6 \%)$ ranging from mild chest discomfort to sudden death. Dyspnea is the most common symptom and this was reported in 73 patients (73/ 147, 49.7\%). Palpitations (36/147, 24.5\%), chest pain (29/ $147,19.7 \%)$ and fatigue $(20 / 147,13.6 \%)$ are also common complaints of symptomatic patients. Syncope or presyncope have been reported in $16(16 / 147,10.9 \%)$ patients, and this was due to severe arrhythmia or obstruction of ventricular outflow tract. Six patients had sudden death due to severe arrhythmia or acute coronary occlusion associated with cardiac lipoma. Very rarely, peripheral embolic events presented as initial symptoms in 3 patients with cardiac lipoma [29-31], which were believed to be caused by the detached thrombi related to arrhythmia (Fig. 3).

Cardiac lipomas at different sites may cause clinical presentation by different pathways. For lipomas within cardiac cavities, obstruction of blood flow may cause symptoms varying from fatigue to even syncope [32-34]. Large pericardial lipomas can be symptomatic by compressing cardiac chambers, vessels or coronary arteries $[21,35,36]$. Myocaridal lipomas are prone to cause conduction abnormalities by compression or infiltration of the conduction system [37, 38]. The size of the cardiac lipoma varied with distribution. In general, pericardial lipomas may grow extensively within the pericardial sac and shared larger size (median, $10.0 \mathrm{~cm}$ ) than

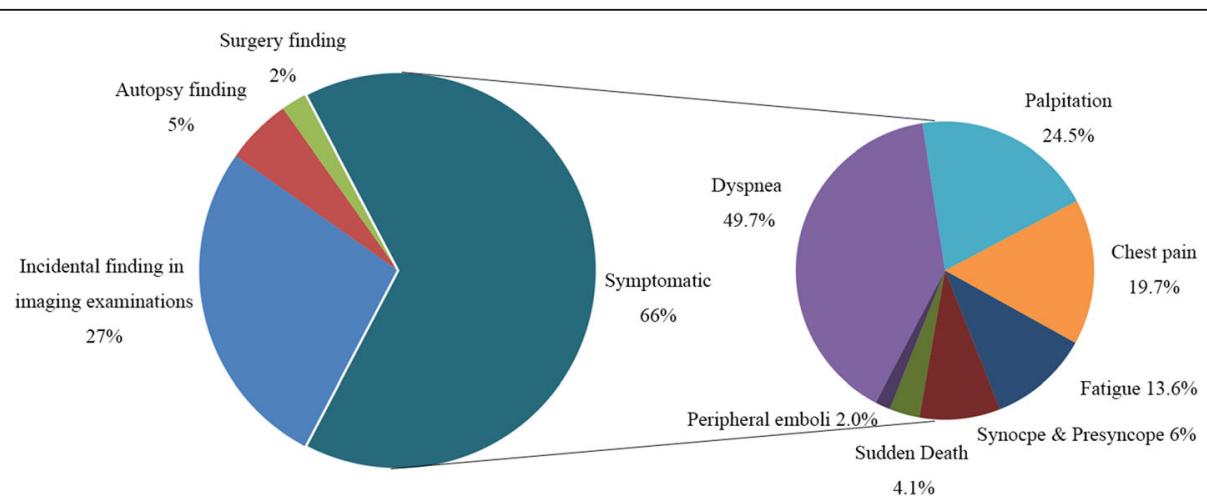

Fig. 2 Site distribution of cardiac lipomas across heart and pericardium of 255 reported cases. LV: left ventricle; RA: right atrium; RV: right ventricle; LA: left atrium 


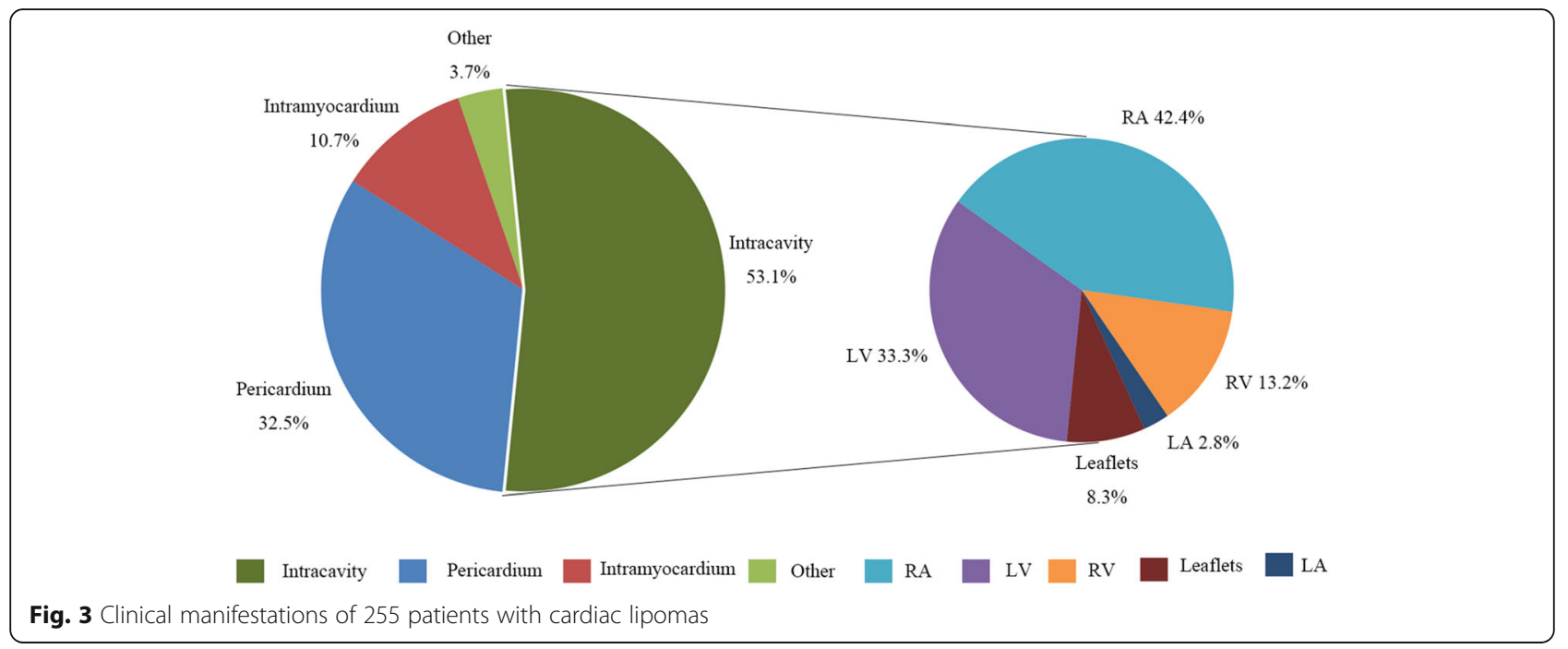

intracavitary $(3.5 \mathrm{~cm})$ and myocardial lipomas $(4.0 \mathrm{~cm})$. Their size is also closely related to the clinical presentation. Median size of symptomatic lipomas is much larger than those found incidentally $(6.1 \mathrm{~cm}$ vs 3.0 $\mathrm{cm})$ (Fig. 4). However, small lipomas at special sites such as cardiac valves may also cause severe symptoms $[39,40]$.

\section{Diagnosis}

Historically, cardiac lipomas were incidental findings during autopsy and cardiothoracic surgery. Noninvasive detection of cardiac masses including lipomas in vivo was not possible until the clinical application of X-ray imaging methods. Lipomas within cardiac cavities may be detected as intracavitary filling defects in cardioangiography [41, 42], while lipomas within pericardial space may show nonspecific signs of an enlarged heart on chest radiograph resembling pericardial effusion [43, 44].
Application of echocardiography made the detection of cardiac masses including lipoma a big step forward. Echocardiography has incomparable advantages of ready availability, convenient operation and radiation-free and it remains the preferred screening method for cardiac masses. Cardiac lipomas usually present as homogenous hyperechoic masses within cardiac chambers or hypoechoic masses within the pericardium $[45,46]$. Although most cardiac lipomas can be sensitively detected and accurately located by echocardiography, their nature cannot be determined based on acoustic property [47]. Acoustic characteristics of lipomas may help exclude cardiac malignancies, and differentiation with other benign lesions such as myxoma is difficult [3].

Emergence of cross-sectional imaging methods including computed tomography $(\mathrm{CT})$ and magnetic resonance imaging (MRI), especially the latter one, made

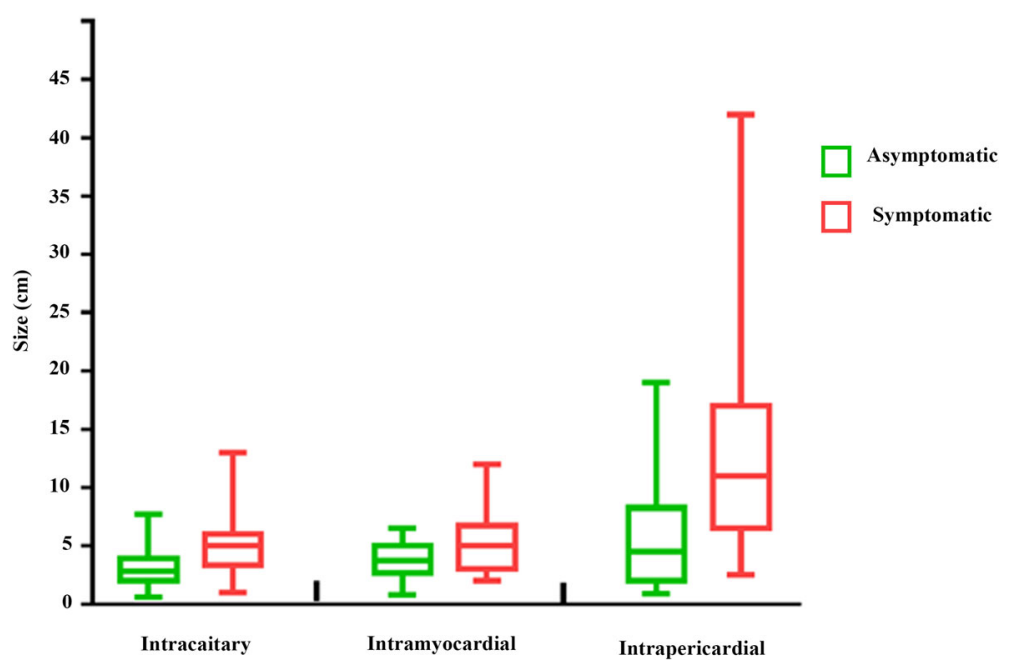

Fig. 4 Comparison of size between intracardiac, intramyocardial and intrapericardial lipomas 

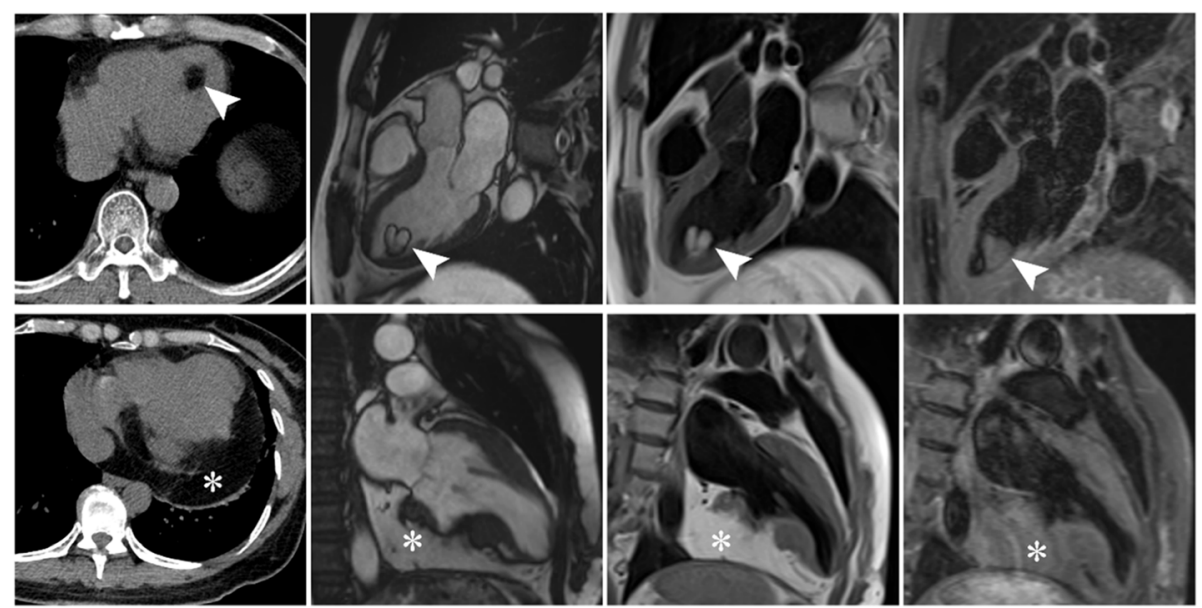

Fig. 5 CT and MR images of left ventricular (triangular arrows) and pericardial (asterisk) lipomas. Imaging features of cardiac lipomas show consistence with subcutaneous fat in all sequences

noninvasive diagnosis of cardiac lipoma possible [48, 49]. Lipomas have entirely the same composition with mature adipose tissue, they show the same imaging appearances with subcutaneous fat in CT and MRI on all sequences [50, 51] (Fig. 5). On CT, they present as homogenous hypodense encapsulated masses with or without linear septa (Hounsfield measurement <- 50) [52]. Signal features of cardiac lipomas show consistence with subcutaneous fat in all MR sequences. Specifically, the complete signal loss of the mass on fat suppression sequence is characteristic for the diagnosis of lipoma [53, 54]. Of note, the black boundary sign in cine sequence due to chemical shift effect is of great help in diagnosing small lipomas [55]. Recently, the tissue mapping technique applied in cardiac imaging has shown great potential to quantitatively diagnose cardiac lipoma [55]. Hemodynamic state, which is commonly evaluated by echocardiography, can also be assessed in cardiac MRI real-time cine sequence. Over all, myocardial infiltration of lipoma can be sensitively detected with cardiac MRI [56]. Like lipoma elsewhere, diagnosis of cardiac lipomas can be established with plain scan, and they do not demonstrate any enhancement on contrast scanning [57]. Though imaging features of cardiac lipoma are highly specific on CT and MRI, it is occasionally necessary to differentiate this benign entity from liposarcoma. The presence of nonuniformly thick septa and masslike nonadipose areas may suggest the diagnosis of liposarcoma [58]. The differentiation between mature cardiac lipomas and well-differentiated liposarcoma may occasionally be difficult by imaging [21]. In summary, echocardiography plays an irreplaceable role in screening of cardiac lipoma, while CT and MRI (particularly MRI), is indispensable for accurate diagnosis and comprehensive evaluation.

\section{Treatment}

There is no guideline on the treatment of cardiac lipoma. Since the first successful removal of a pericardial lipoma reported in 1952 [59], more and more symptomatic cardiac lipomas have been resected, especially after the introduction of the cardiopulmonary bypass technique into cardiac surgery. Radical resection was adopted to relieve symptoms caused by cardiac lipomas in most patients $[60,61]$. Among the included reports, most symptomatic patients $(83.7 \%, 123 / 147)$ underwent resection of cardiac lipomas. Although conservative management may be implemented in patients without symptoms related to cardiac lipoma, 56 patients with $(68.3 \%, 56 / 82)$ asymptomatic cardiac lipomas also received prophylactic resection. Recurrence of cardiac lipomas after surgical resection is extremely rare but has been reported in few cases $[4,12]$. In such cases, incomplete removal due to diffuse infiltration in the myocardium seems to be the contributing factor. Resection of the recurrent lipoma was extremely challenging and heart transplantation may provide the ultimate solution. Over all, radical resection should be considered in all patients with cardiac lipoma, as asymptomatic lipomas may undergo overgrowth and infiltration into the myocardium, and this may result in unfavorable outcomes upon resection. Additionally, close follow-up with imaging methods should be provided toall patients to monitor lipoma overgrowth or recurrence $[62,63]$.

\section{Conclusion}

Cardiac lipoma is a benign primary tumor of the heart. Nonetheless, it may present with clinical symptoms varying from mild discomfort to syncope. Overgrowth of lipoma and infiltration into the myocardium may 
indicate a more severe clinical presentation and unfavorable outcome. Accurate diagnosis and comprehensive evaluation of cardiac lipoma is highly dependent on multimodality imaging methods. Radical resection of the lipoma is the optimal method of treatment in symptomatic patients. Conservative management may be implemented for asymptomatic cardiac lipomas and prophylactic resection should also be considered.

\section{Acknowledgements}

None.

\section{Authors' contributions}

Shenglei Shu: Literature review, Data analysis and Writing - Original draft. Jing Wang: Conceptualization, Resources, Writing - Review \& Editing; Joyman Makamure: Writing - Review \& Editing. Chuansheng Zheng:

Conceptualization, Writing - Review \& Editing, Supervision. The author(s) read and approved the final manuscript.

\section{Funding}

No.

\section{Availability of data and materials}

Not applicable.

\section{Ethics approval and consent to participate}

Not applicable.

\section{Consent for publication}

Not applicable.

\section{Competing interests}

No.

Received: 1 September 2020 Accepted: 4 December 2020

Published online: 06 January 2021

\section{References}

1. Butany J, Nair V, Naseemuddin A, Nair GM, Catton C, Yau T. Cardiac tumours: diagnosis and management. Lancet Oncol. 2005;6(4):219-28. https://doi.org/10.1016/S1470-2045(05)70093-0

2. Ismail I, Al-Khafaji K, Mutyala M, et al. Cardiac lipoma. J Community Hosp Intern Med Perspect. 2015;5(5):28449. Published 2015 Oct 19. https://doi. org/10.3402/jchimp.v5.28449.

3. Sun X, Liu G, Kim H, Sun W. Left ventricular lipoma resected using thoracoscope-assisted limited sternotomy: a case report and literature review. Medicine (Baltimore). 2018;97(31):e11436. https://doi.org/10.1097/ MD.0000000000011436.

4. Zhu J, Liu Y, Xi EP, Zhu SB. A giant symptomatic cardiac lipoma recurring at the fifth year. Int J Clin Exp Med. 2015;8(8):14173-5 Published 2015 Aug 15.

5. Heifetz SA, Parikh SR, Brown JW. Hibernoma of the pericardium presenting as pericardial effusion in a child. Pediatr Pathol. 1990;10(4):575-80. https:// doi.org/10.3109/15513819009067145.

6. Ucak A, Inan K, Onan B, Yilmaz AT. Resection of intrapericardial hibernoma associated with constrictive pericarditis. Interact Cardiovasc Thorac Surg. 2009;9(4):717-9. https://doi.org/10.1510/icvts.2009.209247.

7. Di Tommaso L, Chiesa G, Arena V, Guanella G, Galli C, Roncalli M. Cardiac hibernoma: a case report. Histopathology. 2012;61(5):985-7. https://doi.org/ 10.1111/j.1365-2559.2012.04264.x.

8. Nishio J. Contributions of cytogenetics and molecular cytogenetics to the diagnosis of adipocytic tumors. J Biomed Biotechnol. 2011;2011:524067. https://doi.org/10.1155/2011/524067.

9. Bois MC, Bois JP, Anavekar NS, Oliveira AM, Maleszewski JJ. Benign lipomatous masses of the heart: a comprehensive series of 47 cases with cytogenetic evaluation. Hum Pathol. 2014;45(9):1859-65. https://doi.org/10 1016/j.humpath.2014.05.003.

10. McAllister HAJ, Fenoglio JJ, Fine G. Tumors of the Cardiovascular System. (Atlas of Tumor Pathology, Second Series, Fascicle 15.). NewYork: Armed Force Institute of Pathology; 1978. p. 44-6.
11. Archontakis S, Koumallos N, Demosthenous M, Latsios G, Sideris S. Epicardial right ventricular lipoma presenting with sustained ventricular tachycardia. J Card Surg. 2018;33(8):438-9. https://doi.org/10.1111/jocs.13738.

12. Zeng $L$, Huang $L H$, Tan $H$, et al. Stereotactic body radiation therapy for refractory ventricular tachycardia secondary to cardiac lipoma: a case report. Pacing Clin Electrophysiol. 2019;42(9):1276-9. https://doi.org/10. 1111/pace.13731

13. Peters CM, Kalra N, Sorrell VL. Extensive recurrent cardiac lipoma. J Cardiovasc Comput Tomogr. 2009;3(4):282-3. https://doi.org/10.1016/j.jcct. 2009.03.007.

14. Kondo K, Hagiwara H, Terasawa A. Large cardiac lipoma with pseudoaneurysmal appearance. J Am Coll Cardiol. 2012;60(10):943. https:// doi.org/10.1016/j.jacc.2012.01.080

15. Xie LX, Chen YS, Liu SY. A giant cardiac lipoma associated with ventricular inversion and ventricular aneurysm: ultrasonography and CT imaging findings. Chest. 2012;141(1):241-4. https://doi.org/10.1378/chest.10-2987.

16. Kawarai S, Yaginuma GY, Abe K, Hamasaki A, Ishikawa K, Tanaka D. Left ventricular lipoma with pseudoaneurysm-like appearance. Gen Thorac Cardiovasc Surg. 2010;58(6):279-82. https://doi.org/10.1007/ s11748-009-0528-8

17. D'Souza J, Shah R, Abbass A, Burt JR, Goud A, Dahagam C. Invasive Cardiac Lipoma: a case report and review of literature. BMC Cardiovasc Disord. 2017; 17(1):28. Published 2017 Jan 14. https://doi.org/10.1186/s12872-016-0465-2.

18. Vaughan CJ, Weremowicz S, Goldstein MM, et al. A t(2;19)(p13;p13.2) in a giant invasive cardiac lipoma from a patient with multiple lipomatosis. Genes Chromosomes Cancer. 2000;28(2):133-7 https://doi.org/10.1002/ (sici) 1098-2264(200006)28:2<133::aid-gcc1>3.0.co;2-k.

19. Agacdiken A, Gurbuz Y, Ciftci E, Omay O, Vural A, Ural D. Cardiac lipoma in a patient with proven arrhythmogenic right ventricular dysplasia: a case report. A huge intramyocardial lipoma. Int J Cardiovasc Imaging. 2005;21(4): 463-7. https://doi.org/10.1007/s10554-004-7024-0.

20. Rainer WG, Bailey DJ, Hollis HW Jr. Giant Cardiac Lipoma: Refined Hypothesis Proposes Invagination from Extracardiac to Intracardiac Sites. Tex Heart Inst J. 2016:43(5):461-4. Published 2016 Oct 1. https://doi.org/10.14503/THIJ-15-5342.

21. Kong F, Zhang W, Guo Q. Multiple well-differentiated cardiac liposarcoma with a concomitant myocardial lipoma: a case report. Mol Clin Oncol. 2018; 9(6):617-21. https://doi.org/10.3892/mco.2018.1741.

22. Jr MH. Tumors of the heart and pericardium. In: M. silver, ed. Cardiovascular pathology. 2nd ed: Churchill Livingstone; 1991. p. 1297-333.

23. Wilson S, Frederick J, Braunwald E. Primary tumors of the heart Heart disease A textbook of cardiovascular medicine Philadelphia. Saunders. 1997; 2:1464-77.

24. Zhou QC, Fan P, Peng QH, Zhang M, Fu Z, Wang CH. Prenatal echocardiographic differential diagnosis of fetal cardiac tumors. Ultrasound Obstet Gynecol. 2004;23(2):165-71. https://doi.org/10.1002/uog.979.

25. Williamson BR, Sturtevant NV, Black WC, Brenbridge AN, Teates CD. Epicardial lipoma: a CT diagnosis. Comput Radiol. 1985;9(3):169-71. https:// doi.org/10.1016/0730-4862(85)90160-x.

26. Puvaneswary M, Edwards JR, Bastian BC, Khatri SK. Pericardial lipoma: ultrasound, computed tomography and magnetic resonance imaging findings. Australas Radiol. 2000;44(3):321-4. https://doi.org/10.1046/j.14401673.2000.00821.x

27. Ossola P, Pannone L, Spoladore R, et al. The silent cardiac mass. J Cardiovasc Med (Hagerstown). 2019;20(10):718-20. https://doi.org/10.2459/ JCM.00000000000000839.

28. Bagwan IN, Sheppard MN. Cardiac lipoma causing sudden cardiac death. Eur J Cardiothorac Surg. 2009;35(4):727. https://doi.org/10.1016/j. ejcts.2008.12.022.

29. Erro ME, Ajuria I, Olaz F, et al. Anterior thalamic infarction as initial manifestation of a right atrial lipoma. Can J Neurol Sci. 2009;36(3):379-81. https://doi.org/10.1017/s0317167100007174.

30. Censi S, Squeri A, Baldelli M, Parizi ST. Ischemic stroke and incidental finding of a right atrial lipoma. J Cardiovasc Med (Hagerstown). 2013;14(12):905-6. https://doi.org/10.2459/JCM.0b013e328364bf8b.

31. Zamir D, Pelled B, Marin G, Weiner P. Harefuah. 1995;129(5-6):179-223.

32. Akram K, Hill C, Neelagaru N, Parker M. A left ventricular lipoma presenting as heart failure in a septuagenarian: a first case report. Int J Cardiol. 2007; 114(3):386-7. https://doi.org/10.1016/j.ijcard.2005.11.083.

33. Habertheuer A, Andreas M, Wiedemann D, Rath C, Kocher A. A rare case of obstructive right atrial lipoma. Ann R Coll Surg Engl. 2014;96(7):e39-41. https://doi.org/10.1308/003588414X13946184902965. 
34. Lin HD, Hsu PF, Wu MH, Leu HB, Hsu TL. Images in cardiology: subaortic stenosis caused by left ventricular outflow tract lipoma. Clin Cardiol. 2006; 29(9):421. https://doi.org/10.1002/clc.4960290911.

35. Shenthar J, Sharma R, Rai MK, Simha P. Infiltrating cardiac lipoma presenting as ventricular tachycardia in a young adult. Indian Heart J. 2015;67(4):35961. https://doi.org/10.1016/j.ihj.2015.05.014.

36. Sciuchetti JF, Corti F, Ballabio D, Formica F, Aiello A, Paolini G. Video-assisted thoracic surgical resection of giant cardiac lipoma: a case report. Int J Cardiol. 2008;123(3):e57-8. https://doi.org/10.1016/j.ijcard.2006.11.148.

37. Sakamoto S, Nitta T, Murata H, Yoshio T, Ochi M, Shimizu K. Electroanatomical mapping-assisted surgical treatment of incessant ventricular tachycardia associated with an intramyocardial giant lipoma. J Interv Card Electrophysiol. 2012;33(1):109-12. https://doi.org/10.1007/ s10840-011-9592-y.

38. Jichun L, Zhenlin L, Yuan F, Fabao G. Marked myocardial lipoma of the left ventricle free wall. JBR-BTR. 2014;97(2):103-4. https://doi.org/10.5334/ jbr-btr.22.

39. Chellappan S, Sahu B. Intracardiac lipoma in a child, causing right ventricular outflow obstruction. Asian Cardiovasc Thorac Ann. 2016;24(8): 829-30. https://doi.org/10.1177/0218492316658189.

40. Roberts WC, Grayburn PA, Hamman BL. Lipoma of the mitral valve. Am J Cardiol. 2017;119(7):1121-3. https://doi.org/10.1016/j.amjcard.2016.11.067.

41. CROCKETT JE, DECKER D, REED W, DUNN M, LEGER L. LIPOMA of the heart Am J Cardiol. 1964;14:394-8. https://doi.org/10.1016/0002-9149(64)90084-0.

42. Bradford JH, Nomeir AM, Watts LE. Left ventricular lipoma: echocardiographic and angiographic features. South Med J. 1980;73(5):6635. https://doi.org/10.1097/00007611-198005000-00034.

43. STEINBERG I, SHERMAN RS, Waldman I. Intrapericardial lipoma simulating pericardial effusion. report of two cases. Radiology. 1963:81:949-52. https:// doi.org/10.1148/81.6.949.

44. Shumacker HB Jr, Leshnower AC. Extracavitary lipoma of the heart. Operative resection Ann Thorac Surg. 1974;18(4):411-4. https://doi.org/10. 1016/s0003-4975(10)64378-0.

45. Araoz PA, Mulvagh SL, Tazelaar HD, Julsrud PR, Breen JF. CT and MR imaging of benign primary cardiac neoplasms with echocardiographic correlation. Radiographics. 2000;20(5):1303-19. https://doi.org/10.1148/ radiographics.20.5.g00se121303.

46. Zhou WX, Wang H, Ruan YM, Yan J, Wei YZ, Liu YL. Zhonghua Er Ke Za Zhi. 2005;43(10):758-61.

47. Evdoridis C, Dimos A, Lachanis S, Mountaki V, Trikas A. Characterization of a right atrial lipoma by transthoracic, contrast and transesophageal echocardiography. Int J Cardiol. 2013;162(3):e70-1. https://doi.org/10.1016/j. ijcard.2012.06.027

48. Andreou J, Leitman BS, McCauley DI, Gouliamos A, Pontifex G, Naidich DP. The use of computed tomography in the assessment of cardiac masses. Comput Radiol. 1983;7(6):355-9. https://doi.org/10.1016/07304862(83)90129-4.

49. Amparo EG, Higgins CB, Farmer D, Gamsu G, McNamara M. Gated MRI of cardiac and paracardiac masses: initial experience. AJR Am J Roentgenol. 1984;143(6):1151-6. https://doi.org/10.2214/ajr.143.6.1151.

50. Restrepo CS, Vargas D, Ocazionez D, Martínez-Jiménez S, Betancourt Cuellar SL, Gutierrez FR. Primary pericardial tumors. Radiographics. 2013;33(6):161330. https://doi.org/10.1148/rg.336135512.

51. Hoey ET, Mankad K, Puppala S, Gopalan D, Sivananthan MU. MRI and CT appearances of cardiac tumours in adults. Clin Radiol. 2009;64(12):1214-30. https://doi.org/10.1016/j.crad.2009.09.002.

52. Díaz Angulo C, Méndez Díaz C, Rodríguez García E, Soler Fernández R, Rois Siso A, Marini DM. Imaging findings in cardiac masses (part I): study protocol and benign tumors. Radiologia. 2015;57(6):480-8. https://doi.org/ 10.1016/j.rx.2015.07.002.

53. Ganame J, Wright J, Bogaert J. Cardiac lipoma diagnosed by cardiac magnetic resonance imaging. Eur Heart J. 2008;29(6):697. https://doi.org/10. 1093/eurheartj/ehm476.

54. Luna A, Ribes R, Caro P, Vida J, Erasmus JJ. Evaluation of cardiac tumors with magnetic resonance imaging. Eur Radiol. 2005;15(7):1446-55. https:// doi.org/10.1007/s00330-004-2603-y.

55. Wijesurendra RS, Sheppard KA, Westaby S, Ormerod O, Myerson SG. The many faces of cardiac lipoma-an egg in the heart! Eur Heart J Cardiovasc Imaging. 2017;18(7):821. https://doi.org/10.1093/ehjci/jex048.

56. Fang $L$, He L, Chen $Y$, Xie M, Wang J. Infiltrating Lipoma of the right ventricle involving the Interventricular septum and tricuspid valve: report of a rare case and literature review. Medicine (Baltimore). 2016;95(3):e2561. https://doi.org/10.1097/MD.0000000000002561.

57. Pruente R, Restrepo CS, Ocazionez D, Suby-Long T, Vargas D. Fatty lesions in and around the heart: a pictorial review. Br J Radiol. 2015;88(1051):20150157. https://doi.org/10.1259/bjr.20150157.

58. Kransdorf MJ, Bancroft LW, Peterson JJ, Murphey MD, Foster WC, Temple HT. Imaging of fatty tumors: distinction of lipoma and well-differentiated liposarcoma. Radiology. 2002;224(1):99-104. https://doi.org/10.1148/radiol. 2241011113.

59. MAURER ER. Successful removal of tumor of the heart. J Thorac Surg. 1952; 23(5):479-85.

60. Miralles A, Bracamonte L, Soncul H, et al. Cardiac tumors: clinical experience and surgical results in 74 patients. Ann Thorac Surg. 1991;52(4):886-95. https://doi.org/10.1016/0003-4975(91)91241-m.

61. Elbardissi AW, Dearani JA, Daly RC, et al. Survival after resection of primary cardiac tumors: a 48-year experience. Circulation. 2008;118(14 Suppl):S7-S15. https://doi.org/10.1161/CIRCULATIONAHA.107.783126.

62. Hananouchi Gl, Goff WB 2nd. Cardiac lipoma: six-year follow-up with MRI characteristics, and a review of the literature. Magn Reson Imaging. 1990; 8(6):825-8. https://doi.org/10.1016/0730-725x(90)90021-s.

63. Al-Sabeq B, Autry K, Nabi F. Do I look fat in this? Multimodality imaging findings of a cardiac Lipoma. Methodist Debakey Cardiovasc J. 2019:15(2): 156-7. https://doi.org/10.14797/mdcj-15-2-156.

\section{Publisher's Note}

Springer Nature remains neutral with regard to jurisdictional claims in published maps and institutional affiliations.
Ready to submit your research? Choose BMC and benefit from:

- fast, convenient online submission

- thorough peer review by experienced researchers in your field

- rapid publication on acceptance

- support for research data, including large and complex data types

- gold Open Access which fosters wider collaboration and increased citations

- maximum visibility for your research: over $100 \mathrm{M}$ website views per year

At $\mathrm{BMC}$, research is always in progress.

Learn more biomedcentral.com/submissions 